\section{BRAZIULIAN JOURNAL}

OF MEDICAL AND BIOLOGICAL RLSH.ARCH

www.bjournal.com.br
ISSN 0100-879X

Volume 43 (03) 226-324 March 2010

BIOMEDICAL SCIENCES

AND

CLINICAL INVESTIGATION

Braz J Med Biol Res, March 2010, Volume 43(3) 257-261

Genetic polymorphism of alcohol-metabolizing enzyme and alcohol dependence in Polish men

H. Cicho -Lach, K. Celiński, J. Wojcierowski, M. Słomka and E. Lis

The Brazilian Journal of Medical and Biological Research is partially financed by
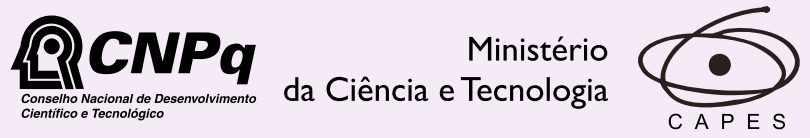

Ministério da Educação

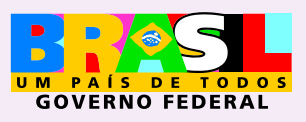

TFAPESP

Institutional Sponsors 


\title{
Genetic polymorphism of alcohol- metabolizing enzyme and alcohol dependence in Polish men
}

\author{
H. Cichoż-Lach ${ }^{1}$, K. Celiński ${ }^{1}$, J. Wojcierowski ${ }^{2}$, M. Słomka ${ }^{1}$ and E. Lis ${ }^{1}$ \\ ${ }^{1}$ Department of Gastroenterology, ${ }^{2}$ Department of Medical Genetics, \\ Medical University of Lublin, Lublin, Poland
}

\begin{abstract}
Alcohol dependence poses a serious medical and sociological problem. It is influenced by multiple environmental and genetic factors, which may determine differences in alcohol metabolism. Genetic polymorphism of the enzymes involved in alcohol metabolism is highly ethnically and race dependent. The purpose of this study was to investigate the differences, if present, in the allele and genotype frequency of alcohol dehydrogenase 1B (ADH1B), ADH1C and the microsomal ethanol-oxidizing system (MEOS/CYP2E1) between alcohol-dependent individuals and controls and also to determine if these genotypes cause a difference in the age at which the patients become alcohol dependent. The allele and genotype frequencies of ADH1B, ADH1C, and CYP2E1 were determined in 204 alcohol dependent men and 172 healthy volunteers who do not drink alcohol (control group). Genotyping was performed by PCR-RFLP methods on white cell DNA. ADH1B*1 (99.3\%) and ADH1C*1 (62.5\%) alleles and ADH1B*1/*1 $(\mathrm{N}=201)$ and $A D H 1 C^{*} 1 /{ }^{*} 1(N=85)$ genotypes were statistically more frequent among alcohol-dependent subjects than among controls ( 99.3 and $62.5 \%, \mathrm{~N}=201$ and 85 vs 94.5 and $40.7 \%, \mathrm{~N}=153$ and 32, respectively). Differences in the CYP2E1 allele and genotype distribution between groups were not significant. The persons with $\mathrm{ADH} 1 \mathrm{C}^{*} 1 /{ }^{*} 1$ and $\mathrm{CYP} 2 \mathrm{E} 1{ }^{*} \mathrm{C} 1 /{ }^{*} \mathrm{C} 2$ genotypes became alcohol dependent at a considerably younger age than the subjects with $\mathrm{ADH} 1 \mathrm{C}^{*} 1 /{ }^{*} 2, \mathrm{ADH} 1 \mathrm{C}^{*} 2 /{ }^{*} 2$ and CYP2E $1{ }^{*} \mathrm{C} 1 /{ }^{*} \mathrm{c} 1$ genotypes $\left(28.08,25.67\right.$ years vs 36.0, 45.05, 34.45 years, respectively). In the Polish men examined, $A D H 1 C^{*} 1$ and $\mathrm{ADH}_{1 \mathrm{~B}^{*} 1}$ alleles and $\mathrm{ADH} 1 \mathrm{C}^{*} 1 /{ }^{*} 1$ and $\mathrm{ADH} 1 \mathrm{~B}^{*} 1 /{ }^{*} 1$ genotypes favor alcohol dependence. The ADH1B*2 allele may protect from alcohol dependence. However, subjects with $\mathrm{ADH} 1 \mathrm{C}^{*} 1 /{ }^{*} 1$ and $\mathrm{CYP} 2 \mathrm{E} 1{ }^{*} \mathrm{C} 1 /{ }^{*} \mathrm{C} 2$ genotypes become alcohol dependent at a considerably younger age than the subjects with $\mathrm{ADH} 1 \mathrm{C}^{*} 1 /{ }^{*} 2, \mathrm{ADH} 1 \mathrm{C}^{*} 2 /^{*} 2$ and $\mathrm{CYP} 2 \mathrm{E} 1{ }^{*} \mathrm{C} 1{ }^{*} \mathrm{c} 1$ genotypes.
\end{abstract}

Key words: CYP2E1 gene polymorphism; ADH gene polymorphism; Alcohol dependence; Age of dependence onset

\section{Introduction}

In Poland, about $10 \%$ of the population abuse alcohol and people treated for alcohol dependence account for about $2.5 \%$ of the population. Estimates show that $20-40 \%$ of Polish patients hospitalized have an alcohol problem and their illness often resulted from alcohol abuse. Alcohol dependence does not develop in all drinking individuals. In the Polish population, even among those consuming large amounts of alcohol systematically, dependence occurs only in $3 \%$ of cases. It is assumed that this fact may be associated, apart from multiple environmental factors, with differences in alcohol metabolism (1). Alcohol metabolism is one of the biological determinants that can significantly influence drinking behavior and the development of alcohol dependence (2). Alcohol dehydrogenase (ADH), aldehyde dehydrogenase and microsomal ethanol-oxidizing system (MEOS/CYP2E1) allele and genotypes occur at different frequencies in particular ethnic groups, and their role in the development of alcohol dependence differs between races and populations (3-11). These enzymes play a role in the variation in health effect outcomes seen in different populations owing to alcohol consumption. These include differences in expression of phenotype, in locus heterogeneity, in risk alleles, and in population structure (12). Genes coding for ethanol-metabolizing enzymes are referred to as alcoholic genes. Alcohol dependence is considered to be a multigene disease (13).

Knowledge of genetic predisposition to alcohol dependence can permit control this social phenomenon in the future. It may be the basis for the treatment of alcohol dependence by inhibition of alcohol gene expression in the genome, allowing the incorporation of therapeutic genes that can modify the expression of disease-predisposing

Correspondence: H. Cichoż-Lach, 20-814 Lublin, ul.Sikorskiego 1/75, Poland. Fax: +48-8-1740-0068. E-mail: Lach.halina@wp.pl

Received August 13, 2009. Accepted January 26, 2010. Available online February 5, 2010. Published March $12,2010$. 
genes, an effect that can last from months to years (14). For the implementation of this idea it is of a practical value to know the time frame for possible preventive treatment actions. It can be observed that age at which people become alcohol dependent varies widely. No reports have been published so far about the possible relationship between polymorphism of the alcohol-metabolizing gene and age of alcohol dependence onset.

The aim of the present study was to compare the differences, if present, in ADH1B, ADH1C, and CYP2E1 allele and genotype frequency between alcohol-dependent individuals and controls, and to examine if these genotypes are associated with a difference in the age at which the patient became alcohol dependent.

\section{Material and Methods}

A group of 204 men - alcohol-dependent subjects aged 20 to 78 years and 172 healthy male volunteers aged 18 to 72 years as a control group - participated in the study. The group of alcohol-dependent subjects included patients consuming more than $80 \mathrm{~g}$ pure ethanol a day for at least 2 years. Alcohol history and the data concerning the age at which the patients became alcohol dependent were obtained with a face-to-face interview. All subjects met the DSM-IV diagnostic criteria for alcohol dependence (15). The alcohol-dependent patients were recruited from the Department of Therapy of Addiction to Alcohol and Department of Gastroenterology, Medical University of Lublin. Their age at onset of alcohol dependence was determined on the basis of medical history concerning their alcohol intake, which sometimes was detailed by contacting family members or friends (after patient's consent), and was assumed to be the earliest date they met the DSM-IV diagnostic criteria for alcohol dependence.

The control group included healthy volunteers who do not drink alcohol at all or occasionally drink such a small quantity of alcohol (no more than $10 \mathrm{~g}$ pure ethanol a year) that they can be considered to be non-drinkers. This information was collected with a face-to-face interview. Control subjects had no evidence of chronic disease or of the presence of disease at physical examination and had normal laboratory test results. They were recruited from the students and personnel of the Medical University of Lublin.

All the patients in this study were Caucasians. The study was approved by the Bioethics Committee of the Medical University of Lublin, Poland, and all subjects gave written informed consent to participate.

Genomic DNA was isolated from peripheral blood with $0.5 \mathrm{M} \mathrm{EDTA}(16)$. For the detection of polymorphism in the $\mathrm{ADH} 1 \mathrm{~B}$ gene the polymerase chain reaction-restriction fragment length polymorphism technique was used on white cell DNA (17). The primers for amplification were ADH1B 247, ADH1B 303, ADH1B 290, ADH1B 424, and $A D H 1 B$ 352. The amplified product was digested with the Maelll enzyme (Roche Applied Science, USA) and with the Alul enzyme (MBI Fermantas, Germany), subjected to $4 \%$ agarose or $12 \%$ polyacrylamide gel electrophoresis, and stained with ethidium bromide or silver nitrate (17).

For the detection of polymorphisms in the ADH1C gene the primers used for amplification were ADH1C 321 and ADH1C 351 (17). The amplified product was digested with Sspl enzyme (MBI Fermantas), subjected to 3\% agarose gel electrophoresis and stained with ethidium bromide (17).

For the detection of CYP2E1 gene polymorphisms in the 5'-flanking region of the P4502E1 gene, CYP2E J8 and CYP2E J9 were used as the primers for amplification (18). The amplified product was digested with Pstl (MBI Fermantas) or Rsal enzyme (MBI Fermantas), subjected to $2 \%$ agarose gel electrophoresis, and stained with ethidium bromide (18).

\section{Statistical analysis}

The $x^{2}$ test or the Fischer exact test was used to compare genotypes and alleles between the groups. The Mann-Whitney test was used to determine if genotype was associated with the age at which the patients became alcohol dependent. The level of significance was set at $P<0.05$ in all analyses. $X^{2}$ goodness of fit tests were used to study agreement with Hardy-Weinberg equilibrium. All calculations were done using the Statistica PL software.

\section{Results}

In the alcohol-dependent group, $\mathrm{ADH} 1 \mathrm{C} * 1$ allele was detected in $62.5 \%$ of the subjects, and ADH $1 C^{*} 1 /{ }^{*} 1$ genotype in 85 patients, a significantly higher frequency compared to the control group (Table 1). Similarly, ADH1B*1 allele and $A D H 1 B^{*} 1 / * 1$ genotype frequencies were significantly higher in the group of alcohol-dependent subjects than among non-drinkers. However, ADH1B*2 allele and $\mathrm{ADH}^{*} \mathrm{~B}^{*} 1{ }^{*} 2$ heterozygotic genotype were significantly more frequent in the control group than among the alcohol-dependent subjects. Differences in CYP2E1 allele and genotype distribution between alcohol-dependent subjects and controls were not statistically significant. The genotype distribution of all groups studied fitted the expected Hardy-Weinberg equilibrium.

The patients with homozygotic $\mathrm{ADH} 1 \mathrm{C}^{*} 1 /{ }^{*} 1$ genotype became alcohol dependent significantly earlier than the patients with $\mathrm{ADH} 1 \mathrm{C}^{*} 1 /{ }^{*} 2$ and $\mathrm{ADH}_{1} \mathrm{C}^{*} 2{ }^{*} 2$ genotypes (Table 2). The average age of the patients with ADH1B*1/*1 genotype who became alcohol dependent was 28.93 years and was lower than the age of those with the ADH1B* $1 /{ }^{*} 2$ genotype. However, it was impossible to analyze the results statistically since the groups differed in size, nor was it possible to state conclusively if a certain type of ADH1B*1/*2 genotype affected the age at which the patients became alcohol dependent. The patients with the CYP2E $1{ }^{*} \mathrm{c} 1 /{ }^{*} \mathrm{C} 2$ 
genotype became alcohol dependent significantly earlier than the persons with homozygotic CYP2E $1{ }^{*} \mathrm{c} 1{ }^{*} \mathrm{c} 1$ genotype.

Table 1. ADH1C, ADH1B and CYP2E1 allele and genotype frequencies in alcohol-dependent patients and controls.

\begin{tabular}{|c|c|c|c|}
\hline & $\begin{array}{l}\text { Alcohol-dependent } \\
\text { subjects }(N=204)\end{array}$ & $\begin{array}{l}\text { Controls } \\
(\mathrm{N}=172)\end{array}$ & $P$ \\
\hline ADH1C alleles (\%) & & & $<0.001$ \\
\hline *1 & $62.5 \%$ & $40.7 \%$ & \\
\hline *2 & $37.5 \%$ & $59.3 \%$ & \\
\hline ADH1C genotypes $(\mathrm{N})$ & & & $<0.001$ \\
\hline$* 1 / * 1$ & 85 & 32 & \\
\hline$* 1 / * 2$ & 88 & 76 & \\
\hline${ }^{*} 2 /{ }^{*} 2$ & 31 & 64 & \\
\hline ADH1B alleles (\%) & & & $<0.001$ \\
\hline *1 & $99.3 \%$ & $94.5 \%$ & \\
\hline *2 & $0.7 \%$ & $5.5 \%$ & \\
\hline ADH1B genotypes $(\mathrm{N})$ & & & $<0.001$ \\
\hline$* 1 / * 1$ & 201 & 153 & \\
\hline$* 1 /{ }^{*} 2$ & 3 & 19 & \\
\hline${ }^{*} 2 /{ }^{*} 2$ & 0 & 0 & \\
\hline CYP2E1 alleles (\%) & & & $>0.05$ \\
\hline${ }^{*} \mathrm{c} 1$ & $97.8 \%$ & $98.8 \%$ & \\
\hline${ }^{*} \mathrm{c} 2$ & $2.2 \%$ & $1.2 \%$ & \\
\hline CYP2E1 genotypes (N) & & & $>0.05$ \\
\hline${ }^{*} \mathrm{c} 1 /{ }^{*} \mathrm{c} 1$ & 195 & 168 & \\
\hline${ }^{*} \mathrm{c} 1 /{ }^{*} \mathrm{c} 2$ & 9 & 4 & \\
\hline${ }^{*} \mathrm{c} 2 /{ }^{*} \mathrm{c} 2$ & 0 & 0 & \\
\hline
\end{tabular}

Statistical comparisons between groups were made with the $x^{2}$ test or the Fischer exact test.

Table 2. ADH1C, ADH1B and CYP2E1 genotypes and mean age when 204 patients became alcohol dependent.

\begin{tabular}{lrrc}
\hline & $\mathrm{N}$ & Age (years) & $\mathrm{P}$ \\
\hline ADH1C genotypes & & & $<0.001$ \\
${ }^{*} 1 /{ }^{*} 1$ & 85 & $28.08 \pm 5.73$ & \\
${ }^{*} 1 /{ }^{*} 2$ & 88 & $36.0 \pm 5.47$ & \\
${ }^{*} 2 /{ }^{*} 2$ & 31 & $45.05 \pm 4.74$ & \\
ADH1B genotypes & & & $\mathrm{ND}$ \\
${ }^{*} 1 /{ }^{*} 1$ & 201 & $28.93 \pm 8.0$ & \\
${ }^{*} 1 /{ }^{*} 2$ & 3 & $35.0 \pm 0$ & \\
$\mathrm{CYP} 2 \mathrm{E} 1$ genotypes & & & $<0.001$ \\
${ }^{*} \mathrm{C} 1 /{ }^{*} \mathrm{C} 1$ & 195 & $34.45 \pm 8.0$ & \\
${ }^{*} \mathrm{C} 1 /{ }^{*} \mathrm{C} 2$ & 9 & $25.67 \pm 3.56$ & \\
\hline
\end{tabular}

Age reported as means \pm SD. Statistical comparisons were made with the Mann-Whitney test. ND = statistical analysis not possible.

\section{Discussion}

The key issue in alcohol dependence is to identify predisposing factors in addition to defining those that lead to alcoholic damage to the digestive organs. Race and gender differences in alcohol tolerance and differences in individual predisposition to develop alcohol addiction have resulted in progress in research. Predisposition to alcohol dependence is affected by multiple environmental and genetic factors in a complicated way (19). Family and twin studies estimated about a $60 \%$ hereditary rate for alcohol dependence. Many lines of evidence obtained by different methods, e.g., gene-manipulated animals, linkage of human genome and genetic association studies, are accumulating information regarding the genetic components involved in alcohol dependence (20). Genetic polymorphisms of the genes encoding alcohol metabolism enzymes and neurotransmitter signaling molecules in dopamine, GABA, opioid, and serotonin systems have been shown to be involved substantially in individual variation of susceptibility to alcohol dependence $(19,21)$.

Studies regarding $A D H 1 C * 1$ among whites are more contradictory and show ambiguous findings: no correlation $(13,22,23)$, protection against alcohol dependence $(3)$ or inconclusive results $(24,25)$. Borras at al. (3) and Espinos et al. (22), who studied Europeans, found that the ADH1C*1 allele was more frequent in alcohol-dependent subjects than among non-drinkers. Similarly, the results of the present study show that the ADH1C*1 allele and $\mathrm{ADH} 1 \mathrm{C}^{*} 1 /{ }^{*} 1$ genotype were detected significantly more frequently in the alcohol-dependent group than in the control group. These data suggest that the $\mathrm{ADH} 1 \mathrm{C}^{*} 1$ allele and $\mathrm{ADH} 1 \mathrm{C}^{*} 1 /{ }^{*} 1$ genotype are likely to favor alcohol dependence. Different results were obtained in studies of Asian populations (2628 ), which showed that the ADH1C*1 allele has protective effects against excessive alcohol consumption.

The results of studies of Asian and European populations show that ADH1B*1 predominated among alcohol addicts and suggest a high risk of alcohol addiction $(9,26-$ 29). Hence, these investigators emphasize the importance of $\mathrm{ADH}_{1 \mathrm{~B}}{ }^{*} 2$ protection against developing alcohol dependence $(3,24,30-37)$. Our results agree with those of other studies presented above and disagree with the study by Vidal et al. (38) on the Spanish population. We found that the $\mathrm{ADH}_{1 \mathrm{~B}}{ }^{\star} 2$ alleles were significantly rarer among alcohol-dependent subjects than among the controls. Thus, we believe the $\mathrm{ADH}_{1 \mathrm{~B}^{*} 2}$ alleles may decrease the risk of developing alcohol dependence in Polish individuals.

In all populations, the CYP2E $1^{*} \mathrm{C} 2$ allele is generally considerably less frequent than the CYP2E $1{ }^{*} \mathrm{C} 1$ allele (9). The CYP2E1* $\mathrm{C} 2$ alleles are more common among Asians than Caucasians (7). Studies evaluating the association between CYP2E1 polymorphism and alcohol dependence in different races have provided contradictory results. Some studies found the CYP2E $1{ }^{*} \mathrm{C} 2$ allele as a risk factor 
for alcoholism $(18,33,39)$, while others did not detect this relationship $(38,40)$. Our study did not find differences in CYP2E1 allele or genotype distribution between alcoholdependent subjects and controls.

There has been no research published on the influence of certain genetic factors on the age at which people become alcohol dependent. Our results here show that the $\mathrm{ADH} 1 \mathrm{C}^{*} 1{ }^{*} 1$ and $\mathrm{CYP} 2 \mathrm{E} 1{ }^{*} \mathrm{C} 1{ }^{*} \mathrm{C} 2$ genotypes incline the patients to become alcohol dependent at a significantly younger age compared to those who have the $\mathrm{ADH} 1 \mathrm{C}^{*} 1 /{ }^{*} 2$, $\mathrm{ADH} 1 \mathrm{C}^{*} 2 /{ }^{*} 2$ or $\mathrm{CYP} 2 \mathrm{E} 1{ }^{*} \mathrm{C} 1 /{ }^{*} \mathrm{C} 1$ genotype. This observation can be of fundamental importance for the use of screening procedures in possible prevention against alcohol dependence. Since no similar studies regarding other races and populations are available, it is not possible to state if similar conclusions would apply to patients from other geographical regions such as Asia, Africa or other countries in Europe. Many factors, such as environmental, familial and somatic ones, may combine to affect the age at onset of alcohol

\section{References}

1. Samochowiec A, Mordasewicz A, Arentowicz G, Samochowiec J. [Addiction pathogenesis in genetic research]. Psychiatria 2005; 2: 9-18.

2. Caballeria J. Current concepts in alcohol metabolism. Ann Hepatol 2003; 2: 60-68.

3. Borras E, Coutelle C, Rosell A, Fernandez-Muixi F, Broch M, Crosas B, et al. Genetic polymorphism of alcohol dehydrogenase in Europeans: the $A D H 2 * 2$ allele decreases the risk for alcoholism and is associated with ADH3*1. Hepatology 2000; 31: 984-989.

4. Chao YC, Young TH, Tang HS, Hsu CT. Alcoholism and alcoholic organ damage and genetic polymorphisms of alcohol metabolizing enzymes in Chinese patients. Hepatology 1997; 25: 112-117.

5. Eng MY, Luczak SE, Wall TL. ALDH2, ADH1B, and ADH1C genotypes in Asians: a literature review. Alcohol Res Health 2007; 30: 22-27.

6. Eriksson CJ, Fukunaga T, Sarkola T, Chen WJ, Chen CC, Ju $\mathrm{JM}$, et al. Functional relevance of human adh polymorphism. Alcohol Clin Exp Res 2001; 25: 157S-163S.

7. Iwahashi K, Matsuo Y, Suwaki H, Nakamura K, Ichikawa Y. CYP2E1 and ALDH2 genotypes and alcohol dependence in Japanese. Alcohol Clin Exp Res 1995; 19: 564-566.

8. Ogurtsov PP, Garmash IV, Miandina GI, Guschin AE, Itkes AV, Moiseev VS. Alcohol dehydrogenase ADH2-1 and ADH2-2 allelic isoforms in the Russian population correlate with type of alcoholic disease. Addict Biol 2001; 6: 377383.

9. Stephens EA, Taylor JA, Kaplan N, Yang CH, Hsieh LL, Lucier GW, et al. Ethnic variation in the CYP2E1 gene: polymorphism analysis of 695 African-Americans, European-Americans and Taiwanese. Pharmacogenetics 1994; 4: 185-192.

10. Zintzaras E, Stefanidis I, Santos M, Vidal F. Do alcoholmetabolizing enzyme gene polymorphisms increase the risk dependence. Our findings may be limited to the sample studied and it is an open question whether they can be generalized. Further investigations on larger samples and different populations should shed light on this issue.

In conclusion, $\mathrm{ADH} 1 \mathrm{C}^{*} 1$ and $\mathrm{ADH}_{1 \mathrm{~B}^{*} 1}$ alleles and $\mathrm{ADH}_{1 \mathrm{C}}{ }^{*} 1{ }^{*} 1$ and $\mathrm{ADH}_{1} \mathrm{~B}^{*} 1{ }^{*} 1$ genotypes favor alcohol dependence among Polish men. On the other hand, the $\mathrm{ADH}_{1} \mathrm{~B}^{\star} 2$ allele may protect from alcohol dependence. The persons with $\mathrm{ADH} 1 \mathrm{C}^{*} 1 /{ }^{*} 1$ and $\mathrm{CYP} 2 \mathrm{E} 1{ }^{*} \mathrm{C} 1 /{ }^{*} \mathrm{C} 2$ genotypes become alcohol dependent at a considerably younger

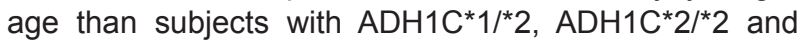
CYP2E $1{ }^{*} \mathrm{C} 1 /{ }^{*} \mathrm{C} 1$ genotypes.

\section{Acknowledgments}

A major part of this study was supported by the Polish State Committee for Scientific Research (\# N N402 244635).

of alcoholism and alcoholic liver disease? Hepatology 2006; 43: 352-361.

11. Agarwal DP. Genetic polymorphisms of alcohol metabolizing enzymes. Pathol Biol 2001; 49: 703-709.

12. Russo D, Purohit V, Foudin L, Salin M. Workshop on Alcohol Use and Health Disparities 2002: a call to arms. Alcohol 2004; 32: 37-43.

13. Lake J. The genetics of alcoholism. Concentration upon alcohol dehydrogenase (ADH). http//www.biol.sc.edu/-elygen/ Jenny\%20Lake.htm.

14. Ocaranza P, Quintanilla ME, Tampier L, Karahanian E, Sapag A, Israel Y. Gene therapy reduces ethanol intake in an animal model of alcohol dependence. Alcohol Clin Exp Res 2008; 32: 52-57.

15. Grant BF, Harford TC, Hasin DS, Chou P, Pickering R. DSMIII-R and the proposed DSM-IV alcohol use disorders, United States 1988: a nosological comparison. Alcohol Clin Exp Res 1992; 16: 215-221.

16. Madisen L, Hoar DI, Holroyd CD, Crisp M, Hodes ME. DNA banking: the effects of storage of blood and isolated DNA on the integrity of DNA. Am J Med Genet 1987; 27: 379-390.

17. Groppi A, Begueret J, Iron A. Improved methods for genotype determination of human alcohol dehydrogenase $(\mathrm{ADH})$ at $\mathrm{ADH} 2$ and $\mathrm{ADH} 3$ loci by using polymerase chain reaction-directed mutagenesis. Clin Chem 1990; 36: 17651768.

18. Hayashi S, Watanabe J, Kawajiri K. Genetic polymorphisms in the 5'-flanking region change transcriptional regulation of the human cytochrome P450IIE1 gene. J Biochem 1991; 110: 559-565.

19. Li TK. Pharmacogenetics of responses to alcohol and genes that influence alcohol drinking. J Stud Alcohol 2000; 61: 5-12.

20. Dick DM, Bierut LJ. The genetics of alcohol dependence. Curr Psychiatry Rep 2006; 8: 151-157. 
21. Fromme $\mathrm{K}$, de Wit $\mathrm{H}$, Hutchison KE, Ray L, Corbin WR, Cook TA, et al. Biological and behavioral markers of alcohol sensitivity. Alcohol Clin Exp Res 2004; 28: 247-256.

22. Espinos C, Sanchez F, Ramirez C, Juan F, Najera C. Polymorphism of alcohol dehydrogenase genes in alcoholic and nonalcoholic individuals from Valencia (Spain). Hereditas 1997; 126: 247-253.

23. Gilder FJ, Hodgkinson S, Murray RM. ADH and ALDH genotype profiles in Caucasians with alcohol-related problems and controls. Addiction 1993; 88: 383-388.

24. Crabb DW, Matsumoto M, Chang D, You M. Overview of the role of alcohol dehydrogenase and aldehyde dehydrogenase and their variants in the genesis of alcohol-related pathology. Proc Nutr Soc 2004; 63: 49-63.

25. Whitfield JB, Nightingale BN, Bucholz KK, Madden PA, Heath AC, Martin NG. ADH genotypes and alcohol use and dependence in Europeans. Alcohol Clin Exp Res 1998; 22: 1463-1469.

26. Chen CC, Lu RB, Chen YC, Wang MF, Chang YC, Li TK, et al. Interaction between the functional polymorphisms of the alcohol-metabolism genes in protection against alcoholism. Am J Hum Genet 1999; 65: 795-807.

27. Maezawa Y, Yamauchi M, Toda G, Suzuki H, Sakurai S. Alcohol-metabolizing enzyme polymorphisms and alcoholism in Japan. Alcohol Clin Exp Res 1995; 19: 951-954.

28. Nakamura K, Iwahashi K, Matsuo Y, Miyatake R, Ichikawa $Y$, Suwaki $H$. Characteristics of Japanese alcoholics with the atypical aldehyde dehydrogenase $2 * 2$. I. A comparison of the genotypes of ALDH2, ADH2, ADH3, and cytochrome $\mathrm{P}-4502 \mathrm{E} 1$ between alcoholics and nonalcoholics. Alcohol Clin Exp Res 1996; 20: 52-55.

29. Loew M, Boeing H, Sturmer T, Brenner H. Relation among alcohol dehydrogenase 2 polymorphism, alcohol consumption, and levels of gamma-glutamyltransferase. Alcohol 2003; 29: 131-135.

30. Chambers GK, Marshall SJ, Robinson GM, Maguire S, Newton-Howes J, Chong NL. The genetics of alcoholism in Polynesians: alcohol and aldehyde dehydrogenase genotypes in young men. Alcohol Clin Exp Res 2002; 26: 949-955.

31. Kim SA, Kim JW, Song JY, Park S, Lee HJ, Chung JH. Asso- ciation of polymorphisms in nicotinic acetylcholine receptor alpha 4 subunit gene (CHRNA4), mu-opioid receptor gene (OPRM1), and ethanol-metabolizing enzyme genes with alcoholism in Korean patients. Alcohol 2004; 34: 115-120.

32. Lorenzo A, Auguet T, Vidal F, Broch M, Olona M, Gutierrez $\mathrm{C}$, et al. Polymorphisms of alcohol-metabolizing enzymes and the risk for alcoholism and alcoholic liver disease in Caucasian Spanish women. Drug Alcohol Depend 2006; 84: 195-200.

33. Sun F, Tsuritani I, Yamada Y. Contribution of genetic polymorphisms in ethanol-metabolizing enzymes to problem drinking behavior in middle-aged Japanese men. Behav Genet 2002; 32: 229-236.

34. Wall TL. Genetic associations of alcohol and aldehyde dehydrogenase with alcohol dependence and their mechanisms of action. Ther Drug Monit 2005; 27: 700-703.

35. Osier MV, Lu RB, Pakstis AJ, Kidd JR, Huang SY, Kidd KK. Possible epistatic role of $\mathrm{ADH} 7$ in the protection against alcoholism. Am J Med Genet B Neuropsychiatr Genet 2004; 126B: 19-22.

36. Luczak SE, Glatt SJ, Wall TL. Meta-analyses of ALDH2 and ADH1B with alcohol dependence in Asians. Psychol Bull 2006; 132: 607-621.

37. Osaka R, Nanakorn S, Sakata R, Nishiyori A, Shibata A, Nakamura J, et al. Alcohol dehydrogenase-2 and aldehyde dehydrogenase-2 genotypes and male alcohol use disorders in Khon Kaen, north-east Thailand. Psychiatry Clin Neurosci 2003; 57: 37-45.

38. Vidal F, Lorenzo A, Auguet T, Olona M, Broch M, Gutierrez C, et al. Genetic polymorphisms of ADH2, ADH3, CYP4502E1 Dra-I and Pst-I, and ALDH2 in Spanish men: lack of association with alcoholism and alcoholic liver disease. $J$ Hepatol 2004; 41: 744-750.

39. Konishi T, Calvillo M, Leng AS, Feng J, Lee T, Lee H, et al. The ADH3*2 and CYP2E1 c2 alleles increase the risk of alcoholism in Mexican American men. Exp Mol Pathol 2003; 74: 183-189.

40. Pastorelli R, Bardazzi G, Saieva C, Cerri A, Gestri D, Allamani A, et al. Genetic determinants of alcohol addiction and metabolism: a survey in Italy. Alcohol Clin Exp Res 2001; 25: 221-227. 